\title{
'Stepping Out': Enabling Community Access to Green Space through Inter-disciplinary Practice Learning in Plymouth, UK
}

\author{
Maria Tighe, ${ }^{1}$ Andrew Whiteford ${ }^{2}$ \& Janet Richardson ${ }^{1}$ \\ ${ }^{1}$ School of Nursing \& Midwifery, Faculty of Health and Human Sciences, Plymouth University, UK \\ ${ }^{2}$ School of Social Work, Faculty of Health and Human Sciences, Plymouth University, UK \\ Corresponding author: \\ Dr Maria Tighe, School of Nursing \& Midwifery, Faculty of Health Education and Society, Plymouth \\ University, 7 Portland Villas, Drake Circus, Plymouth PL4 8AA, UK \\ Email: Maria.Tighe@plymouth.ac.uk
}

\begin{abstract}
This paper presents a small-scale action research study of public health nursing and social work students' practice-based learning. The study aimed to identify collaborative opportunities to improve access to green space for community residents in Plymouth, in the United Kingdom (UK). The student experience was nested within 'Stepping Stones to Nature' (SS2N), a city-wide initiative enabling local residents' access to green space. A local health impact assessment (HIA) provided an over-arching partnership framework. The pedagogical aim was for students to learn and work together to make a real contribution to people's lives. This innovation was enabled through the Plymouth University's Teaching and Learning Strategy (2009-2012) and the Social Work programmes established structures for student's learning in Community Development Projects (CDP). Through the action research methodology, we explored the potential for community development as a framework for inter-disciplinary learning. Our findings suggest that an inter-disciplinary pedagogy emerges through a community development framework for students' practice-based learning.

Inter-disciplinary learning was achieved through student-centred learning networks; a key shared concept was 'Wellbeing and Sustainability'. Within this new practice-based context student learning is tenuously situated, yet positively achieved. Through changing health and social behaviours, student participation demonstrates: a) professional knowledge and skills, b) collaborative working, and c) change agency. SS2N partnerships enabled student's evidence-based practice and highlighted that a student's individual relationship to green space was critical to their engagement. Pedagogy that places inter-disciplinary practice learning at the core of teaching and learning about sustainability, environment and access to green space is indicated, alongside collaborative working to enable students to actively contribute to reducing health inequalities.
\end{abstract}

Keywords: sustainability, inter-disciplinary, public health nursing, social work, action research 


\section{Introduction}

Current shifts in UK public health policy reflect a local government leadership of public health activities. The movement emphasises inter-disciplinary working and collaborative health promotion to improve the lives of local families and communities (Marmot 2010, DoH 2011, 2012). Healthier lifestyles are encouraged through community engagement with a wider range of services in the voluntary, public and private sectors. New approaches to public health advocate social responsibility, strengthening community resilience and building self-confidence among the more marginalised and least franchised in our society. Epidemiological evidence of the relationship between people's living environment, poverty and health suggests an urgent need for multi-level intervention (Marmot 2010, Dorling \& Thomas 2011). Some scientists argue that resource-intensive technological growth that is dependent on fossil fuels is unsustainable for people and the planet (Egger \& Swinburn 2010). Global health inequalities reveal the environmental relationship between consumerism, climate change and obesity (Richardson \& Wade 2009, Waters et al. 2011). Social justice is advocated through public health partnerships, which aim to develop 'glocal' (Kickbusch 1999, p451) capacity to reduce the burden of illness and disease (Kickbusch 2009, Marmot 2010). Intersectoral partnerships that demonstrate synergetic 'trust, leadership and efficiency' are most likely to succeed in reducing health inequalities (Jones \& Barry 2011, p408). Such inter-relational aspects of partnership working are relevant to the community-building capacity of health and social care professionals working at the interface between family and population health (Marmot 2010, DoH 2011, 2012).

The five pedagogical principles of 'education for sustainability' (EfS) are reinforced by: futures thinking, critical and creative thinking, participation and participatory learning, systematic thinking and partnerships Ryan \& Tilbury (2011, p5). Kagawa (2007), Ryan \& Brooks (2007) and Sterling (2012) also highlighted the important relationship between ESD and inter-disciplinarity, describing the need to embed inter-sectorial working into core curricula and attending to students' individual need to meet accreditation criteria. The UK higher education (HE) sector faces significant practical challenges in preparing social work and nursing graduates for inter-disciplinary public health work. For example, although inter-professional working is a formal learning requirement for both disciplines, Becher \& Trowler (2001) suggest that academic cultures persistently resist collaborative working. Winter \& Cotton $(2012$, p1) highlight the use of the term 'hidden curriculum' to explain how educators and students act to overcome perceived or real resistance to their engagement with a sustainability agenda, most likely through their involvement in pro-environmental learning behaviours. As follows, we demonstrate the challenges for students and others involved in their learning, and the simultaneous potential for an inter-disciplinary pedagogy through commitment to a community development framework for students' practice-based learning (Blake et al. 2009).

\section{Stepping Stones to Nature (SS2N)}

Plymouth City Council (PCC) describes SS2N as a four-year project that aims to improve local residents' engagement with parks and natural spaces (SS2N 2011). Funded by a Big Lottery 'Access to Nature' programme, the project promotes collaborative working with residents and other agencies in order to improve health and social opportunities. A university-led 'Health Impact Assessment' (HIA) was undertaken for this project; the results of this highlighted the known health and wellbeing benefits of improving local residents' access to green space, and suggested the value of the HIA framework in promoting multi-agency working (Richardson et al. 2012). With the support of the Centre 
for Sustainable Futures (CSF), along with programme mentors, managers, and the SS2N research lead, the authors utilised their prior involvement in the HIA to extend their academic and practice learning roles to evaluate the SS2N student experience.

\section{Background}

International policy on higher education towards sustainable development (United Nations WCED 1987, Dawe et al. 2005) has evolved apace with the UK movement towards 'Education for Sustainability' (EfS) (Huckle \& Sterling 1996, Sterling \& Scott 2008) and 'Education for Sustainable Development' (ESD) (Ryan 2011, Ryan \& Tilbury 2011). Through practice-based educational collaboration the authors discovered that an equal stake in the discourse surrounding wellbeing was located for them around a shared academic concern for sustainability; and, more specifically, the recurring and emergent link between sustainability and broader considerations of the 'green' or natural environment in health and social experience (Richardson \& Wade 2009, Blake 2010). Locally, Kagawa (2007) had identified a dissonance between theory and practice in that the Plymouth University's social work and nursing students (as compared to other groups of students) demonstrated a significant lack of engagement with the concept of sustainability, and sustainable development. Nicols et al. (2009), Richardson et al. (2009) and Nicols \& Richardson (2011) report similar local problems in NHS managers' capacity to engage with sustainable approaches to waste management.

Existing attempts to broaden out the concept of wellbeing (to include sustainability) respond to a globalised public health agenda and a renewed focus on the social determinants of health. Kagawa (2007), Richardson \& Wade (2009) and Goodman \& Richardson (2010) argue for the emphasis in social work, nursing and HE to be aligned to an 'ecocentric' model with less emphasis on the individual and biomedical explanations of health and disease. Richardson et al. (2009), and Nichols et al. (2009) suggest that NHS health service managers and workers have a responsibility for health promotion by working to prevent climate change, while Nancy (2010) reminds social workers of their responsibilities within a global community, as 'change agents' towards a more sustainable world. Recent shifts in UK health and social policy suggest integrated community-based partnerships involving local authorities and the voluntary sector, and calling upon SCPHNs (health visitors) to reclaim their community-building capacity (DoH 2011). Public health nursing and social work collaboration on such a project was therefore strongly indicated.

\section{Social Work Community Development Projects}

The BA (Hons) Social Work programme is committed to taking a 'transformative' approach to education that opens up possibilities for students, through their practice and in their lives. Students are encouraged to advocate for sustainability in partnership with the communities in which they work and live (Whiteford et al. 2010). There is a rich history of 'community-university partnerships' which support the 'Community Development Project' (CDP) concept (Chan et al. 1997). The CDP model views students as a potential resource and by drawing on their existing skills, knowledge and experience enables them to make a real contribution to people's lives whilst undertaking assessed practice-based learning. The integration of CDP into the Social Work programme (since 2001) most readily demonstrates teaching and learning about sustainability and environmental issues (Blake et al. 2009).

Located within a critical analysis of social work as social action, the CDP has actively generated placement capacity through its alliance with Non-Governmental Organisations, where services, support and development are increasingly being provided. Students can make a real, and much needed contribution to people's lives and directly experience the 
resourcefulness of individuals and communities at a time when so many state services are being restructured and reduced.

From a pedagogical stance the programme values reflection, critical analysis and action in its approach, actively links and integrates learning from the range of experiences available and most critically, embeds practice at its core (Adamson 2011). A key module was designed to link practice and theory around core themes and objectives instead of agreed content and timings (Bellinger \& Kagawa 2010). Teaching staff were thus enabled to plan and deliver content flexibly in response to the students' emerging practice learning experience. This was achieved through small 'study groups' that advocate sustainable thinking and action through a 'social learning' process that Tilbury (2007) argues is the context for sustainability itself.

This flexible CDP practice learning is a collaborative resource which makes links between statutory, voluntary and community-based initiatives that support environmental concerns for the broader 'greening' of society. In a review of inter-disciplinarity and sustainability in $\mathrm{HE}$, Blake et al. $(2009$, p51) highlighted positive cases of curriculum change at Plymouth University and recommended that 'the projects might encompass an inter-disciplinary and inter-professional dimension'. Linking social work to the undergraduate Nursing and Public Health programmes has enabled both Nursing and Social Work to advance and strengthen their discipline agendas in terms of embedding sustainability into the curriculum. In reaching across and linking disciplines held within separate departmental boundaries we were able to address some of the institutional and organisational barriers that exist (Kagawa 2007, Ryan 2011); particularly the problematic tension between sustainable action and ideology, which inhibits transformative learning (Sterling \& Scott 2008, Winter \& Cotton 2012). As follows, in this small-scale action research study, we suggest that transformative learning is enabled by 'hidden curriculum' elements of community development, which enabled public health nursing and social work students' collaborative working with SS2N to improve environmental awareness of the benefits of access to green space.

\section{Public Health Nursing and Learning in Practice}

In UK specialist community public health nursing (SCPHN) Practice the role of practice-based learning is a developing research topic. Byers (2002) identified the mentoring roles of community practice teachers (CPT) in enabling SCPHN practice-based learning. A deeper analysis is provided by Poulton \& Lyons (2008) comparative study of SCPHN students' and practice teachers' views on practice-based competence. Poulton suggests generic public health competencies are self-perceived learning achievements that appear more rhetoric than reality. For example, students perceive that they demonstrate higher levels of confidence than their practice teachers in public health skills such as 'evidence-based practice' and 'population health needs assessment'. The authors recommend assisting practice teachers in keeping up to date through an academic programme of continuing professional development. Similar findings are suggested by Freudenstein \& Yates (2001) who surveyed primary care practitioners in south-west England. They suggest real gaps in SCPHN skills-training, particularly in preparing practitioners for leading multi-skilled service planning, delivery and evaluation. This action research study aimed to part-redress the theory-practice gap, developing SCPHN students' opportunities for wider placement learning in the context of educational and training requirements (Nursing and Midwifery Council 2004) and local workforce needs. According to the NMC criteria (2004) the SCPHN student experience must include wider placement activity, the nature of which is negotiated between the student and their practice teacher/assessor. Unlike the resource-based ethos of a social work community development placement, this wider activity is 'voluntary', although related learning outcomes are 
demonstrated through the students' practice-based portfolio of evidence - allied to the academic modules that comprise the NMC-validated BSc (Hons) SCPHN programme. All practice placements are subject to UK National Health Service (NHS) and allied arrangements for health and safety assessment.

\section{Social Work and Nursing Students' Participation in SS2N}

Over the course of one year, five first-year undergraduate Social Work students and one BSc SCPHN (school nurse) student undertook practice learning with SS2N. The pedagogical aim was for students to work together to make a real contribution to people's lives. This was an innovation for students in terms of practice learning, and was enabled though collaboration with the Social Work programme's established structures for students' learning in Community Development Projects (CDP).

The social work and public health nursing students had different learning pathways to practical engagement with the project. The undergraduate social work students were required to complete a minimum of 200 days of assessed practice learning over the 3 years, 50 of which are completed in their first year. The practice learning at this foundational stage consists of a combination of individual work where student responsibility is similar to that of a new volunteer; group work organised around a CDP and time shadowing/observing local authority social work. The particular balance of these elements is decided on the basis of individual students' experience and learning needs and contributes to an overall assessment of their 'readiness to practice' in their second year. Thus, the social work students were formally allocated to SS2N whilst the placement offered an SCPHN student volunteer the opportunity to work under the supervision of the social work practice learning manager, and to reflect on a new environmental-health-partnership approach to health improvement. Following email and classroom invitation, five SCPHN students initially volunteered. Four later dropped out; two explaining that travel, time constraints and illness meant they could not commit. One SCPHN student (Nora) (all names are pseudonyms), a school nurse student, committed to working alongside social work students on this project. The placement was negotiated with the student's then practice teacher and mentor as a five-day wider placement opportunity, which would enable her learning progression through maintenance of a reflective portfolio and allied assessment on two taught modules. Academic support was provided from the Social Work placement management team affiliated to the Centre for Educational Practice \& Placement Learning (CEPPL). All students were informed that they would be invited to participate in the action research study. It was anticipated that SS2N would offer all students collaborative learning experiences to promote leadership skills through: a) effective partnership working and b) engagement with sustainability initiatives. It was not intended that their research participation would affect their learning opportunities. Ethical approval for the study was obtained from the Plymouth University Research Ethics Committee.

\section{Action Research}

The action research study aimed to develop and evaluate SS2N as a collaborative practice learning experience for SCPHN and social work students. The objectives were to:

1. establish the value of SS2N as an inter-disciplinary learning opportunity;

2. evaluate SS2N potential for students' learning about green space, health and well being. 


\section{Design}

A 'case-based' action research design was chosen to allow a qualitative exploration of the practice learning setting (SS2N) through triangulated data collection methods. McNiff \& Whitehead (2002) acknowledge the overlap between the case-based method and an action research design and also distinguish action research from evaluative research in terms of its cyclical process and egalitarian purpose. The purpose of action research is to influence or change some aspect of the research or practice as the learning process evolves (Robson 2002). In this case (SS2N) the involvement of social work and public health nursing students was an active participatory aim. Although the students were not recruited as co-researchers, their participation in small interdisciplinary group discussions and in one-to-one interviews furthered each new cycle of action. Upon reflection, some gaps between theory and practice were identified; concepts relating to 'community development' and 'sustainability'were deemed too vague or inaccessible. Instead, 'Wellbeing and Sustainability' provided a shared language for social work and nursing discussions and the students more readily used this framework to take ownership of their learning. For example, with tutorial support they identified the academic and profession-specific criteria which they felt best related to 'Wellbeing and Sustainability' and one student applied a literature review of the evidence base on green space and wellbeing to create an individual learning contract with her mentor and practice learning manager. This was enabled by the action research process which integrated practice learning with theory and encouraged the students' reflective capacity through seeking out their perspectives. During the study the whole team approach was identified by the students as a positive enabling feature and subsequently referred to as the 'student-centred learning network'. This included social work and nursing mentors, practice teachers, lecturers and practice learning managers, as well as the SS2N HIA researchers (Richardson et al. 2012) and SS2N co-ordinators. In addition, the students used their personal interview transcripts to write their reflective portfolios which contributed towards their accredited professional learning. One nursing student later wrote an article on her experience of SS2N for publication in a professional journal while a social work student (Sally) volunteered to lead the development of a 'friends group' for local residents.

The principles and practices of action research were shared with participants through the provision of information leaflets (allied to the ethical approval process) and in discussions at the SS2N research steering group meetings, interdisciplinary student meetings (CDP) and in the SS2N practice learning meetings led by the social work team. In order to ground the action research method in wider SS2N activities the data collection required triangulated sources and methods. The three methods chosen were semi-structured interviews, participant observation and documentary research. These complementary methods maximised the qualitative data collection opportunities through reflective cycles of action. For example, participant observation included a visit to the students' practice learning site to explore the wider SS2N partnership project. Findings from the action research informed the wider health impact assessment, which aimed to include a focus on student experience (Richardson et al. 2012). Documentary research involved a literature review. Semi-structured interviews furthered one-to-one discussions with staff and students: the format for the interviews was influenced by learning from the site visit, the contemporaneous SS2N, student and staff meetings and documentary research. Seven semi-structured interviews were undertaken by one of the authors (MT) with at least one representative member of each of the six stakeholder groups: University lecturing staff, SS2N co-ordinators, NHS practice teachers/mentors, Social Work CDP team, the SS2N research steering group and the social work and nursing students. 


\section{Sample}

To reflect the SS2N case-based context of student-centred learning a purposive sample was obtained; at least one representative from each of the six stakeholder groups identified above were invited to participate. Each group represented a partnership stakeholder organisation. This included the participating students, academic lecturers, practice learning team (CDP) and practice teacher/mentor participants, and the project co-ordinators in the SS2N field of practice and research.

\section{Data Collection and Analysis}

The qualitative design was chosen to allow flexibility of data collection tools and methods and to deepen the scope of analysis. Following ethical approval from Plymouth University the action research commenced; each cycle of action learning led to a change in research process or suggested a review of a previous task (McNiff \& Whitehead 2002). For example, the initial practice learning discussions led to two of the authors a visits a SS2N learning site, which stimulated questions for the interview schedule while providing feedback to the practice learning team and partnership research group. This improved opportunities for students and staff participation through maximising the opportunities to identify and express views at particular points of engagement with SS2N. The action learning cycles were enabled by triangulating the methods of participant observation, semi-structured interviews and documentary research (research steering group notes and SS2N reports). In interviews the students referred to critical learning incidents which were further explored in action research cycles of literature reviewing, site visits and discussions with the teaching, practice and research teams.

This level of analysis was supported by comparative thematic analysis undertaken by one of the authors (MT) with peer review of the student transcripts undertaken by a second author (AW). The action research cycles informed the dual role of implementing changes in practice learning while evaluating changes in practice. To enhancethe depth and rigour of thematic analysis, cross-referencing of the triangulated data sources was undertaken: NVivo7 software was used to support this data management process and data saturation was reached when no new categories emerged. This resulted in the identification of one core theme of 'changing health and social behaviours' which was further divided into the three sub-themes. The data collection process was iterative and informed by two of the authors' cross-checking a sample of transcripts as well as participant validation of their interview data.

\section{Findings}

A summary of the study findingsfocuses on the experience of the SCPHN student (Nora) and her documented learning process, which incorporated her working across traditional boundaries in order to meet her learning needs. Basic field analysis (Lewin 1951) demonstrated how SS2N collaborative drivers are countered by restraining NHS forces, which suggest professional disciplinary resistance to SCPHN student engagement with the project. The case-based triangulation of relevant literature, documents, observational site visits and stakeholder interviews revealed one core category of 'changing health and social behaviours'. Changing health and social behaviours is demonstrated through three sub-themes which illuminate the stakeholders' narrative of the students'transformative learning:

\section{Knowledge and Skills}

Whilst learning was achieved, it was apparent that students had difficulty in applying the concept of 'sustainability' to their practice learning. This supports the findings by 
Blake et al. (2009) on the pedagogical challenge of not strictly defining sustainability for social work students engaging with community development projects, in that the links to practice learning were at times opaque. In this case, the social work student (Sally) acknowledges the lack of a CDP definition, but also notes the value of classroom teaching in preparing for CDP.

Sally: “I don't think I've seen a definition, but community development for me is like a social perspective - looking at the strengths and weaknesses of the community and working on sustainability and community ownership, you know. It's something that I think social work is heading towards. Again, it's the need to focus on the community and the support networks and that does involve access to green spaces because, you know, exercise, and using the green spaces helps with mental health, physical health and general well-being. But that's not something that at the start I would have linked together at all, actually, so, it's been quite good looking at it in that way. It's been quite good making the link with our CD placement and the general teaching because they were talking about community development in a wider sense and then putting that into practice with SS2N."

The Nursing \& Midwifery Council (2004) standards for SCPHN proficiencies offer a flexible framework for the SCPHN students' wider placement learning. However, while the study participants agreed that the SCPHN student demonstrated achievement of identified competencies, NHS role constraints are identified by the SCPHN mentor (Bevan) and SCPHN student (Nora) as a limiting feature of student engagement with community development practice.

Bevan: "This wider public health placement helped address the areas of practice-based competency. However there are difficulties. I think this way of working is harder for school nurses to see the relevance and apply it. I had to be advised by the CPT (community practice teacher) who helped me to relate it (with the student) to the different domains (NMC competency framework). The thing about green space is that it is distinct and well we just don't have that much room for manoeuvre."

Plaza et al. (2007) advocate an eclectic pedagogical approach which not only focuses upon students' knowledge and skills acquisition but also encourages a reflexive focus. Reflective evidence may be presented by students to demonstrate their ability to manage more complex situations (Endacott et al. 2004). This is aligned to the transformative learning experience suggested by Winter \& Cotton (2012) and Mezirow (2000). The study by Blake et al. (2009) suggests that whilst a multitude of understandings emerged from classroom-based teaching around sustainability, some students were less comfortable with a diffuse and undefined term when applied to the CDPs. Findings from the interviews in this study also suggest that an understanding of sustainability in the form of reflexive enquiry and an exploration of power was more readily seized by students. Reflection was encouraged through their participation in the research study and they used this opportunity to identify the ways in which they negotiated practical challenges and utilised their academic skills to ground their experiences.

\section{Collaborative Working}

During her wider placement experience, Nora (SCPHN student) consulted with the SS2N project co-ordinators, practice teacher, mentor, and module lecturers who agreed that she undertake a 'health needs assessment' during her visits to a local Children's Centre. This competency-based activity helped Nora to facilitate access to green space for learning for disabled children who attended the Centre regularly: 
Nora: "I think that the school (Centre), they're already doing a lot for the students. But they had not accessed the green space, and it's very, very, close. But they needed a way to access it."

Through adapting a 'health-needs-assessment' framework Nora describes the importance of bridging the theory-practice gap. She also commented upon the unforeseen ways in which the school children engaged with the SS2N activity:

Nora: “We went out with six students. And we took them for a little tour and we told them what we were thinking of doing. They had so many ideas, and when we came back, one of the children really stood out. We sat down and talked about, 'What did you like about the site, what did you not like, and what do you think we can improve? 'At first he didn't say anything, and then he said, 'I think maybe we should look at what other people have done.'So, all the students, they had access to computers, all of them started to look at what could be there, and the teacher, she said... 'He never says anything,' he rarely has any suggestions."

This was a critical learning incident for Nora, who went on to develop a practice tool to include green space assessment within a 'whole-school health needs assessment'. She considered how this child's communication reflected the transformative action of nature, as well as her own learning about the value of research:

Nora: "I just thought, there's a researcher there, you know he wants to go and research, 'What have other people done? What can we do?' And I just thought, that's evidence-based."

Meanwhile, Sally, the social work student, discusses how her perceptions of CDP and social work change as she reflects on her collaborative engagement with the SS2N project.

Sally: "I think it's been really valuable, this community development, because I hadn't had any experience before and we're training to be social workers and we're putting on our wellies and walking through the woods. We didn't make the link but I think it's really opened our eyes to see how to engage with different people, the importance of community sustainability and taking ownership and getting every individual involved. Looking at the SS2N project manager's role and how there are so many roles that are so similar to social work. That's been noticeable with the work (SS2N project co-ordinators) have done. That they work together and especially with going into the schools. Even if it's to do with safeguarding, you can move that into any area you work in, that kind of collaborative working."

Whilst Sally asserts the value of inter-disciplinary collaborative working, Ryan \& Tilbury (2011) have identified real-world difficulties in demonstrating inter-disciplinary education for sustainable developments. They suggest how this is compounded by pedagogical distinctions that remain abstracted rather than applied to intersectoral work. In contrast, Nora (SCPHN student) tells how she developed an evidence-based proposal for a change to school nursing practice. For Nora, this involved her developing a practice tool through a 'whole-school health needs assessment' framework. This eco-centric approach to the school nurse role supports the proactive public health agenda identified by Nurse et al. (2010). Adding a simple question regarding school children's access to outdoor activities changed local practice through integration of an 'access to green space' assessment for learning-disabled students. 


\section{Change Agency}

Nora recognised that she was a school nursing student who is interested in the environment. Although her SS2N involvement with the Children's Centre and School 'filled a gap' in the school nursing service, she describes how this action was challenged in practice. In interview she suggests that her student status afforded a learning opportunity that would not otherwise be encouraged:

Nora: "It was still a bit of a challenge as a student, because my mentor who's extremely encouraging and positive about everything, she still sort of said to me in the beginning 'That's great, but maybe...' she gave other suggestions that would be sort of more relevant to practice,... more easy to do in practice. But I think, because I was a student, when I made the links clear, both my mentor and my CPT were positive about it, whereas if I actually was in practice I'm not sure that would be the case."

In making the evidence about green space benefits clear to her mentor, Nora supports Poulton's (2007) findings, which suggested that SCPHN students' self-perceived achievement of practice-based competencies often differs from their mentors. Below, we utilise Nora's learning experience to illustrate a particular example of how learning objectives were achieved through her 'stepping out' of the traditional student role.

\section{Stepping Out}

Ryan \& Tilbury (2011) assert how real-world links between education for sustainability and inter-disciplinary work remain a significant challenge. In the context of inter-sectorial public health work, Nora made the links between theory and practice through determining an evidence-based rationale for her school nurse involvement in the SS2N project. This rationale draws upon her wider learning and individual initiative to counter the resistance to her 'stepping out' role. Whilst a high level of NHS practice teacher and mentor support enabled her learning, her reflections suggest this was sometimes tolerated rather than encouraged. Her mentor, (Bevan) offered an alternate view of Nora's engagement with SS2N; in stepping outside the usual norms of student behaviour, Nora's assertive behaviour demonstrated her motivation to be a 'change agent' through extending the scope of the local school nurse role.

Bevan: "This SCPHN student was a strong personality and extremely motivated. Also the CPT helped a lot with fitting the process and application to the domains, and so now I feel better equipped to relate this to SCPHN competencies and practice. But this student was less aware of current structures and because of this she was prepared to step over some taken-for-granted boundaries, plus she is a good communicator. Not all students could do that. She has a different sense of what is out there and I think you could say that the project has helped her to step out in a different direction, she may end up working as a public health practitioner rather than as an SCPHN."

A role 'outside' SCPHN practice could therefore be expected for Nora, and whilst this was expressed as a positive career-building outcome, this raises some questions about how professional belonging is achieved. In contrast, the SS2N co-ordinator (Gill) suggested the collaborative benefits outweighed the resources needed to support Nora's learning;

Gill: "I think the benefits greatly outweighed the time input this year and, it's down to the strength of the student, but also coming from a health perspective and being a postgrad student as well, I networked into a whole other area of service provision that perhaps we wouldn't have had the time to scope out. I've 
been able to perhaps link her with other professionals or other areas of work that she wouldn't necessarily have come into contact with; so I think it has been mutually beneficial this year, definitely."

Sally, the social work student, also identified the need to 'step out' as a feature of effective engagement with the sustainable aims of SS2N.

Sally: "Sustainability is about... you know, if you take a step out, it's the community taking ownership and making sure it can continue to grow."

Whilst Sally and Nora proved themselves as individually skilled and motivated students who were keen to participate in this project, it was suggested by the SS2N co-ordinating team that there is a high resource need to support some other students' learning to self-engage with green space, rather than assume that all students could enable change. The SS2N co-ordinators identified variable student skill in facilitating local residents' access to green space. This supports Blake et al. (2009) and Kagawa's (2007) findings, which suggest a more general 'dissonance' in social work and nursing students' attitude to and subsequent engagement with environmental sustainability. In contrast Cotton et al. (2007) illustrated how, despite the fact that many lecturers find the language of ESD inaccessible, there is a fairly high level of support for sustainable development across all disciplines. In this study, the need to change NHS professional behaviours of engagement with children and families (through improving local community residents' access to green space) is an emergent feature of SS2N project aims.

\section{Discussion}

In this study the students who were interviewed demonstrate the transformative learning identified by Winter \& Cotton (2012) and Sterling (2009) as a collaborative feature of education for sustainability and inter-disciplinarity. Winter \& Cotton (2012) illustrated how students learn through participation in pedagogical research. SS2N student involvement in the evaluation of their practice learning was part of this action research process. Through reading their interview transcripts and confirming analytic categories, the students developed their capacity for reflective assignments and portfolio work (Endacott et al. 2004). One of the author's observational visits to a SS2N site (MT) helped develop practice relationships by identifying features of the students' and local residents' engagement with SS2N. This led to a change in the interview guide relating to the students' level of participation and demonstrates the value of triangulating data collection methods to bridge the theory-practice gap.

The implications of the SS2N study findings for social work and public health nursing are similar. The findings support Jones \& Barry (2011) recent study of the factors which facilitate public health partnerships; namely, synergetic trust, leadership and efficiency. This study also builds upon the local study by Blake et al. (2009), which suggests that the holistic model, where sustainability encompasses and integrates political, social, economic and ecological dimensions, might challenge framings of practice that are increasingly managerialist. Our study highlights the positive role of CDP in embedding collaborative inter-disciplinary practice learning for sustainability. In turn, this supports discipline-specific objectives, such as the DoH (2011) framework for reclaiming the SCPHN (health visitors) role in community capacity-building and partnership working. Thus, despite the fact that this action research study is limited by a very small sample size, it nonetheless highlights the multi-agency opportunities for learning through collaborative working for health improvement in local communities. Student learning was largely achieved through engaging with the 'hidden curriculum' of pro-environmental behaviours through the social work CDP opportunity which facilitated their individual engagement with SS2N. At the same 
time, a wider conceptual framework of 'wellbeing and sustainability' was more readily understood than 'community development' by our students.

To conclude, inter-disciplinary student learning was essentially achieved through collaborative 'student-centred learning networks' developed outside the traditional classroom learning context. These networks were enabled through the 'hidden curriculum' of pro-environmental behaviours enabled by the social work CDP, and the broader SS2N research steering partnership which ran alongside the SS2N co-ordination of the project. A key shared concept in this regard was 'Wellbeing and Sustainability'. The three inter-related themes suggest that within the SS2N practice-based context, student learning is tenuously situated yet positively achieved. Through 'changing health and social behaviours' SS2N demonstrates a practical role in: a) the development of professional knowledge and skills; b) collaborative working, and c) change agency. SS2N partnership enabled students' reflective evidence-based practice and highlighted that a student's individual relationship to green space was critical to their level of engagement with the project. Another key factor was the student's preparedness for meeting the aims of the SS2N project. These two factors required attention from both staff and students before any purposeful work could be undertaken and it is through this that most learning occurred.

Future public health nursing and social work students would benefit from improved theory-practice links that demonstrate the eco-centric relation between social justice, sustainability, and health and well-being (Barton \& Grant 2006, Richardson \& Wade 2009, Goodman \& Richardson 2010, Dorling \& Thomas 2011). Health promotion pedagogy that places inter-disciplinary practice learning at the core of teaching and learning about sustainability, environment and access to green space is indicated, alongside improvements in collaborative working that enable students to actively contribute to reducing health inequalities.

\section{Acknowledgments}

Sincere thanks to all participants. Thanks to Professor Debbie Cotton for helpful comments on the first draft of this paper. We are grateful to the SS2N research steering group and the social work practice learning team for facilitating this practical learning opportunity for our students.

\section{References}

Adamson, C.E. (2011) Getting the balance right: critical reflection, knowledge and the social work curriculum. Advances in Social Work and Welfare Education (Special Issue: Critical Reflection: Method and Practice) 13 (1) 29-48.

Barton, H. and Grant, M. (2006) A health map for the local human habitat. Journal of the Royal Society for the Promotion of Public Health 126 (6), 252-261.

Becher, T. and Trowler, P. (2001) Academic tribes and territories. (2nd ed.). Maidenhead: Open University Press.

Bellinger, A. and Kagawa, F. (2010) Learning beyond compliance: a comparative analysis of two cohorts undertaking a first year social work module. Journal of Pedagogic Development 1 (2) ISSN: 2047-3257.

Blake, J., Sterling, S. and Kajawa, F. (2009) Getting it together: interdisciplinarity and sustainability in the higher education institution. Occasional Paper 3. Plymouth: Centre for Sustainable Futures. 
Blake, J. (2010a) Sustainable communities and social work practice learning: reflections on emergent learning partnerships. Journal of Practice Teaching in Health and Social Work 9 (2), 93-114.

Blake, J. (2010b) Community engagement: towards a sustainable future. University of Plymouth Policy Background Paper. Plymouth: Plymouth University, Centre for Sustainable Futures (Teaching \& Learning Development).

Byers, P. (2002) Developing the role of the mentor in post-basic nurse education: East Midlands NHS confederation area. Nurse Education Practice 2 (1), 66-69.

Campbell, M., Fitzpatrick, R., Haines, A., Kinmonth, A., Sandercock, P., Spiegelhalter, D. and Tyrer, P. (2000) Framework for design and evaluation of complex interventions to improve health. British Medical Journal 321 (7262), 694-696.

Chan, C.L.W., Chui, E.W.T., Wong, D.K.P., Tam, V.C.W., Wong, Y.C. and Law, C.K. (1997) Critical reflection on community work education: a social work curriculum addressing social deprivation and poverty. Resource Paper Series No. 30. Hong Kong: University of Hong Kong Department of Social Work and Social Administration.

Cosco, N. (2007) Developing evidence-based design: environmental interventions for healthy development of children in the outdoors. In Open Space: People Space (eds. C. Ward Thompson and P. Travelou). London: Taylor \& Francis.

Cotton, D.R.E., Warren, M.F., Maiboroda, O. and Bailey, I. (2007) Sustainable development, higher education and pedagogy: a study of lecturers' beliefs and attitudes. Environmental Education Research 13 (5), 579-597.

Croucher, K., Mayer, L. and Bretherthon J. (2007) The Links between Greenspaceand Health: A Critical Literature Review. York: University of York.

Dawe, G., Jucker, R. and Martin, S. (2005) Sustainable Development in Higher Education: Current Practice and Future Developments. A Report for the Higher Education Academy. York: Higher Education Academy.

Department of Health (DoH) (2011) Health visitor implementation plan: a call to action 2011-2015. Available at: http://www.dh.gov.uk/prod_consum_dh/groups/dh_digitalassets/ documents/digitalasset/dh_124208.pdf (accessed 21 April 2013).

Department of Health (DoH) (2012a) Improving outcomes and supporting transparency a public health outcomes framework for England, 2013-2016. Available at: http://www.dh. gov.uk/prod_consum_dh/groups/dh_digitalassets/@dh/@en/documents/digitalasset/ dh_132559.pdf (accessed January 2013).

Department of Health (DoH) (2012b) Improving outcomes and supporting transparency a public health outcomes framework for England, 2013-2016. Available at: http://www.dh. gov.uk/prod_consum_dh/groups/dh_digitalassets/@dh/@en/documents/digitalasset/ dh_132559.pdf (accessed January 2013).

Dorling, D. (2011) Opinion: Social inequality and environmental Justice. Environmental Scientist (Journal of the Institution of Environmental Sciences) 19 (3), 9-13.

Dorling, D. and Thomas, B. (2011) Mapping inequalities in Britain. Sociology Review 21 (1), 15-19.

Egger, G. and Swinburn, B. (2010) Planet Obesity: How We Are Eating Ourselves and the Planet to Death. New South Wales: Allen \& Unwin.

Endacott, R., Gray, M.A., Jasper, M.A., McMullan, M., Miller, C., Scholes, J. and Webb, C. (2004) Using portfolios in the assessment of learning and competence: the impact of four models. Nurse Education in Practice (4) 250-257. 
Freudenstein, U. and Yates, B. (2001) Public health skills in primary care in South West England: a survey of training needs, obstacles and solutions. Public Health 115 (6), 4-11.

Goodman, B. and Richardson, J. (2010) Climate change, sustainability and health in UK higher education: the challenges for nursing. In Sustainability Education: Perspectives and Practice across Higher Education (eds. P. Jones, D. Selby and S.S.). London: Earthscan.

Hartig, T. (2007) Three steps to understanding restorative environments as health resources. In Open Space: People Space (eds. P. Travelou and C. Ward Thompson). London: Taylor \& Francis.

Hillsdon, M., Panther, J., Foster, C. and Jones, A.P. (2006) The relationship between access and quality of urban green space with population physical activity. Public Health 120 (12), 1127-1132.

Jones, J. and Barry, M. (2011) Exploring the relationship between synergy and partnership functioning factors in health promotion partnerships. Health Promotion International 26 (4), 408-420.

Kagawa, F. (2007) Dissonance in students' perceptions of sustainable development and sustainability: implications for curriculum change. International Journal of Sustainability in Higher Education 8 (3), 317-338.

Kickbusch, I. (1999) Global public health: re-visiting healthy public health policy at the global level. Health Promotion International 14 (4), 285-288.

Kickbusch, I. (2009) Policy Innovation for Health. Geneva: Springer.

Lewin, K. (1951) Field Theory in Social Science: Selected Theoretical Papers. New York: Harper \& Row.

Marmot, M. (2010) Fair society, healthy lives: the Marmot Review: strategic review of health inequalities in England post-2010. Available at http://www.marmotreview.org (accessed 10 January 2013).

Nancy, L.M. (2008) Social Work in a Sustainable World. Chicago: Lyceum Books.

McNiff, J. and Lomax, P. (1996) You and Your Action Research Project. New York: Routledge Falmer.

McNiff, J. and Whitehead, J. (2002) Action Research: Principles and Practices. Second edition. London: Routledge.

Mezirow, J. (1991) Transformative Dimensions of Adult Learning. San Francisco: Jossey-Bass.

Mezirow, J. (2000) Learning as transformation. San Francisco: Jossey Bass.

Monbiot, G. (2006) Heat: how to Stop the Planet Burning. London: Allen-Lane Penguin.

Nichols, A. and Richardson, J. (2011) Climate change, health and sustainability: a brief survey of Primary Care Trusts in the south-west of England. Perspectives in Public Health 131, 82-84.

Nichols, A., Maynard, V., Goodman, B. and Richardson, J. (2009) Health, climate change and sustainability: a systematic review and thematic analysis of the literature. Environmental Health Insights 3 (63-88).

Nursing and Midwifery Council (2004) Standards of Proficiency for Specialist Community Public Health Nurses. London: Nursing and Midwifery Council.

Nurse, J., Basher, D., Bone, A. and Bird, W. (2010) An ecological approach to promoting population mental health and well-being - A response to the challenge of climate change. Perspectives on Public Health 130 (1), 27-33. 
Plaza, C., Reierson Draugalis, J., Slack, M.K., Skrepnek, G.H. and Sauer, K.A. (2007) Use of reflective portfolios in health sciences education. American Journal of Pharmaceutical Education 71 (2), 34.

Poulton, B. and Lyons, A. (2008) A comparative study of self-perceived public health competencies: practice teachers and qualifying SCPHNs. Community Practitioner 81 (9), 31-34.

Richardson, J. and Wade, M. (2009) Public health threats in a changing climate: meeting the challenges through sustainable health education. In Education and Climate Change: Living and Learning in Interesting Times (eds. D. Selby and F. Kagawa). Abingdon: Routledge Press.

Richardson, J., Kagawa, F. and Nichols, A. (2009) Health, energy vulnerability and climate change: a retrospective thematic analysis of Primary Care Trust policies and practices.

Public Health 123, 765-777.

Richardson, J., Pratt, A., Goss, Z., Sharman, J. and Tighe, M. (2012) Building HIA approaches into strategies for green space use: an example from Plymouth's (UK) Stepping Stones to Nature project. Health Promotion International. Available at DOI: \10.1093/heapro/ das033 (accessed 8 August 2013).

Robson, C. (2002) Real World Research. Oxford: Blackwell.

Ryan, A. and Brooks, C. (2007) ESD Interdisciplinary Discussion Series, Higher Education Academy. Available at http://www.heacademy.ac.uk/projects/detail/esd/ esd_interdisc_series2007 (accessed 16 April 2013).

Ryan, A. (2011) Briefing Paper: Inter-disciplinary sustainability education: insights, momentum and futures. UK Higher Education Academy.

Ryan, A. and Tilbury, D. (2011) Education for Sustainability: a Guide for Educators on Teaching and Learning Approaches. University of Gloucestershire, UK.

Stones, Stepping to Nature (2011) Annual Report June 2010-June 2011. Plymouth: Plymouth City Council.

Sterling, S. and Scott, W. (2008) Education for sustainable development in higher education. Environmental Education Research, Special Issue, 14 (4), 386-396.

Sterling, S. (2009) Towards sustainable education. Environmental Scientist (February), 19-21.

Sterling, S. (2012) The Future Fit Framework - an introductory guide to teaching and learning for sustainability in HE. The Higher Education Academy.

Tilbury, D. (2007) Learning based change for sustainability: perspectives and pathways. In Social Learning towards a Sustainable World (ed. A.E.J. Wals). Netherlands: Wageningen Academic.

United Nations (1987) Our Common Future (The Brundtland Report). New York: United Nations World Commission on Environment and Development.

University of Plymouth (2009) Teaching and Learning Strategy 2009-2012. Plymouth: Plymouth University.

Whiteford, A., Horton, V., Garrard, D., Ford, D. and Butler, A. (2010) Sustaining communities: sustainability in the social work curriculum. In Green Infusions: Embedding Sustainability in the Higher Education Curriculum (eds. D. Selby, S. Sterling and P. Jones). London: Earthscan.

Winter, J. and Cotton, D. (2012) Making the hidden curriculum visible: sustainability literacy in higher education. Environmental Education Research 18 (6), 783-796.

Yin, R.K. (2003) Case Study Research, Design and Methods. Newbury: Sage Publications. 